\title{
The Field Shielding Effect of Mountain on the Lightning Electromagnetic Field
}

\author{
Xiaoyu Peng1, Lei Wang², Jinbo Zhang33, Jiawen Chen³, Bingzhe Dai ${ }^{3}$ \\ ${ }^{1}$ Kunming Power Supply Bureau, Kunming, China \\ ${ }^{2}$ Yunnan Electric Power Test Institute (Group) Co. Ltd., Kunming, China \\ ${ }^{3}$ Nanjing University of Information Science and Technology, Nanjing, China \\ Email:pxybh@163.com,16812084@qq.com, zhangji-nbo92@nuist.edu.cn,chenjw_123@126.com,dbz123123@126.com
}

How to cite this paper: Peng, X.Y., Wang, L., Zhang, J.B., Chen, J.W. and Dai, B.Z. (2020) The Field Shielding Effect of Mountain on the Lightning Electromagnetic Field. Journal of Electromagnetic Analysis and Applications, 12, 15-28.

https://doi.org/10.4236/jemaa.2020.122003

Received: January 4, 2020

Accepted: February 11, 2020

Published: February 14, 2020

Copyright $\odot 2020$ by author(s) and Scientific Research Publishing Inc. This work is licensed under the Creative Commons Attribution International License (CC BY 4.0).

http://creativecommons.org/licenses/by/4.0/

\begin{abstract}
In this paper we have studied the effect of strike to a cone-shaped mountain surrounded by two chains of hills on the lightning vertical electric field and azimuthal magnetic field at different distances, by using two-dimensional finite-difference time-domain (2-D FDTD) method in cylindrical coordinate systems. In order to analyze the electrostatic shielding effect of strike to a cone-shaped mountain surrounded by two chains of hills on the lightning, we chose three mountains, and the left one is stroke by lightning, and the right one is near the obervation site, and the middle one with the top heights increasing from 0 to $2 \mathrm{~km}$ is between them. For the observed point, the electrostatic shielding effect of the right one on the lightning vertical electric field is the most serious, and the electric field is much less than that for strike to flat ground level; compared with the electric field, the shielding effect of the right one on the lightning azimuthal magnetic field becomes less, for most cases, the lightning magnetic field at the observed site is larger than that for flat ground cases mainly due to that of the increment caused by strike to the right mountain. With the increase of distance (e.g., $20 \mathrm{~km}$ from the lightning strike point), the shielding effect of the right mountain on the lightning field becomes less, because the reflected wave from the right mountain bottom plays a more important role over intermediate ranges, and the far radiation electromagnetic field peak value becomes larger due to such a reflecting wave. Therefore, in the lightning detecting technique, we should pay more attention to the effect caused by chains of hills on the lightning location and the estimation of lightning current peak.
\end{abstract}

\section{Keywords}

Lightning Current, Lightning Electromagnetic, Mountain Height, Mountain Inclination, Propagation Path 


\section{Introduction}

The widely used lightning location systems provide lightning return stroke peak currents estimated from the remotely measured electric or magnetic field. For theoretical estimation expressions, the return stroke channel base currents and radiated fields are usually assumed to be proportional each other, with the proportionality coefficient being determined for striking to flat ground with the perfect conductivity [1] [2] [3]. However, due to the complexity of lightning striking process and the propagation effect of lightning-radiated electromagnetic field along the finitely conducting earth, the use of field-to-current conversion factors (FCCFs) for the lightning strike to flat ground appears to be inappropriate for lightning strike to tall objects, especially for the propagation path with the lower conductivity. For example, Azadifar et al. [4] presented the performance analysis of the European Cooperation for Lightning Detection (EUCLID) lightning detection network using current data obtained at the Säntis Tower (located in northeastern of Switzerland), and found that the peak current estimates provided by the EUCLID network were about 1.8 times higher than those from direct measurements. Furthermore, Li et al. [5] presented a theoretical analysis supported by simultaneous records of lightning currents measured at the Säntis Tower and electric fields measured at a distance of about $15 \mathrm{~km}$ from the tower, their results showed that the presence of mountainous terrain around Säntis Tower results in an enhancement of radiated electric field, which is consistent with the overestimation of the EUCLID Network.

Until now, there are many authors that have studied the lightning discharge characteristics for strike to tall objects or mountain top. For the case of lightning strike to tall objects [6]-[17], as a result of transient process in the object, current waveforms can differ significantly at different heights along the object and can exhibit more than one peak (typically, secondary peak is larger than the initial one). At far distances, the lightning-radiated electromagnetic field for strike to an object case can become greater than that for strike to the flat ground. However, at very close distance near the object height or less, it is found that the electric field for strike to object case is reduced relative to the flat ground (e.g. [8] [14]), the experimental confirmation of this shadowing effect is also reported by Mosaddeghi et al. [15]. For strike to mountain top (e.g., [5] and [18] [19] [20] [21]), the lightning-radiated electromagnetic field has much obvious difference from strike to flat ground surface, which will have a much effect on the FCCFs for the estimation of lightning current peak. Soto et al. [18] [19] have presented the lightning-radiated electromagnetic field for strike to different configurations of non-flat lossy ground respectively, and found an enhancement of the vertical and horizontal electric field components for lightning striking a cone-shaped mountain top within a very close distance of $1 \mathrm{~km}$. Khosravi et al. [21] further analyzed the difference of lightning-radiated electromagnetic field for striking tall tower that sits on the flat ground and on a cone-shaped mountain, and it is shown that the electromagnetic field for striking a tower on a cone-shaped 
ground has an enhancement as compared to the case where the tower sits on a flat ground. Also, the mountain cone angle and height as well as the tower height have an effect on the current distribution along the tower and the lightning channel and its corresponding electromagnetic field.

Recently, Hou et al., [2018] compute the lightning vertical electric field and azimuthal magnetic field at ground level at observed distance ranging from 0.3 $\mathrm{km}$ to $50 \mathrm{~km}$ for striking the cone-shaped mountain terrain with different height and inclination angles, and found that the mountain height and inclination angle have much effect on the lightning electromagnetic field both for the close and far observed distance, and in the lightning location technique, we should pay more attention to the effect of strike to mountain height and inclination angles.

However, Hou et al., [2018] simply analyze the effect of one chain of cone-shaped hills on the lightning-radiated electromagnetic field. In fact, the complex topography and geomorphology have much effect on the lightning electromagnetic field propagation (e.g., the field peak value and its arrival time), for example, in the lightning location technique, the the arrival time of the lightning field wave is delay due to the complex topography and geomorphology, which will increase the lightning location error. Therefore, in this paper we will study a more general condition for the effect of strike to a cone-shaped mountain surrounded by several chains of hills on the lightning electromagnetic field, and further analyze the effect of changes of mountain height on the lightning field.

\section{Methodology}

\subsection{2-D FDTD Model for Computing the Lightning-Radiated Electromagnetic Field for Strike to Mountain Terrain}

In order to simulate the effect of non-flat terrains on the lightning-radiated electromagnetic field, the Maxwell equations are solved by using two-dimensional finite-difference time-domain (2-D FDTD) method in cylindrical coordinate systems [22] [23]. Figure 1 shows the configuration of the 2-D FDTD model in cylindrical coordinate systems for lightning striking a cone-shaped mountain surrounded by several chains of hills. The lightning channel is placed on the axis of symmetry. M1, M2 and M3 are the heights of three cone-shaped mountains with the same inclining angle and different heights, respectively. The lightning strikes the M1, and the observed site is near the right side of M3. Therefore, through changing the heights of M1, M2 and M3, respectively, and we can analyze the effect of stroke mountain M1, the mountain M2 that is scattered along the propagation path and the mountain M3 near the observed site, respectively. And $\mathrm{d}$ is the horizontal distance from the lightning channel to the observation point. The simulation dimension is $52 \mathrm{~km} \times 8 \mathrm{~km}$, and the upper and right boundary are surrounded by Convolutional Perfectly Matched Layer absorbing boundary (CPML) [24]. The space step was $\Delta r=\Delta z=5 \mathrm{~m}$, and time step was 8.3 ns. The lightning channel is simulated by a vertical array of current sources [25]. In order to simulate the non-flat ground in the FDTD method, the conformal 


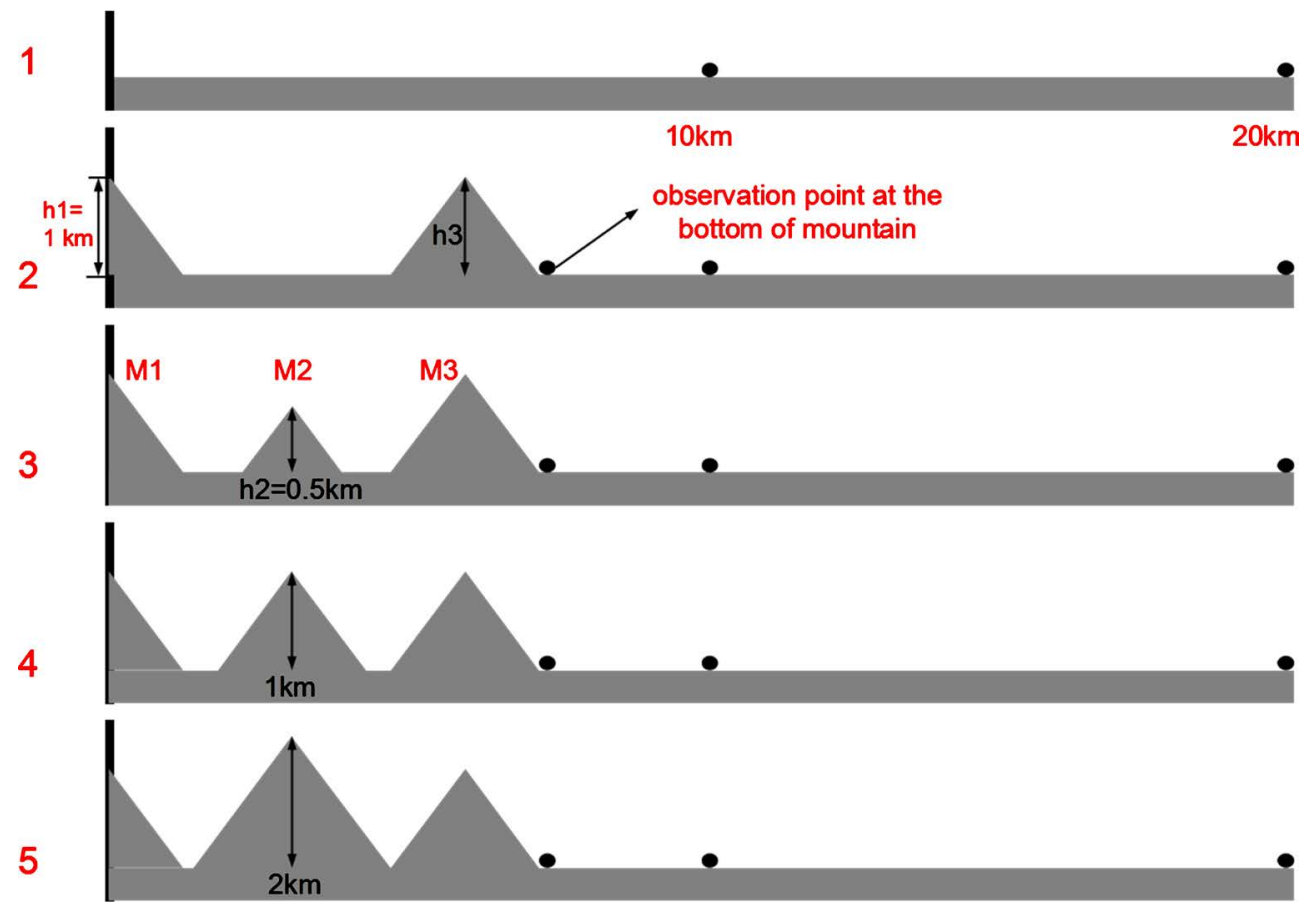

Figure 1. Configuration of the 2-D FDTD model in cylindrical coordinate systems for lightning striking a cone-shaped mountain surrounded by several chains of hills. The lightning channel is placed on the axis of symmetry. M1, M2 and M3 are the heights of three cone-shaped mountains with the same inclining angle and different heights, respectively. $\sigma$ and $\varepsilon$ are the soil conductivity and permittivity, respectively.

FDTD method was used [26] [27]. And the electromagnetic parameters such as the permeability $(\mu)$, the conductivity $(\sigma)$, and the permittivity $(\varepsilon)$ in a boundary cell between ground and air are calculated considering the proportion of the two median on the edges of the cell. Figure 1 also shows the positive directions of the electromagnetic field component vector used in this paper.

\subsection{Validation of our 2D FDTD Codes}

In order to validate our 2D FDTD method codes for considering the effect of strike to mountain terrain, we compare our result with that calculated by finite element method (FEM). Figure 2 shows the compared simulated results between ours and that in [20], all parameters chosen here are the same as that presented by Paknahad et al. [20]. And we can see that ours are approximately the same as that presented in [20], which means our code of 2D FDTD method is correct and can be used to analyze the lightning-radiated electromagnetic field for strike to mountain top.

\section{Computed Results and Analysis}

In this paper we chosen a typical subsequent return stroke channel-base current, with a peak value of $12 \mathrm{kA}$ and a maximum steepness of $40 \mathrm{kA} / \mu \mathrm{s}$, represented by the following Heidler [28] parameters: $\mathrm{I} 01=10.7 \mathrm{kA}, \tau 11=0.95 \mu \mathrm{s}, \tau 12=4.7$ $\mu \mathrm{s}, \mathrm{I} 02=6.5 \mathrm{kA}, \tau 21=4.6 \mu \mathrm{s}, \tau 22=900 \mu \mathrm{s}$, and $\mathrm{n}=2$. The modified transmission 

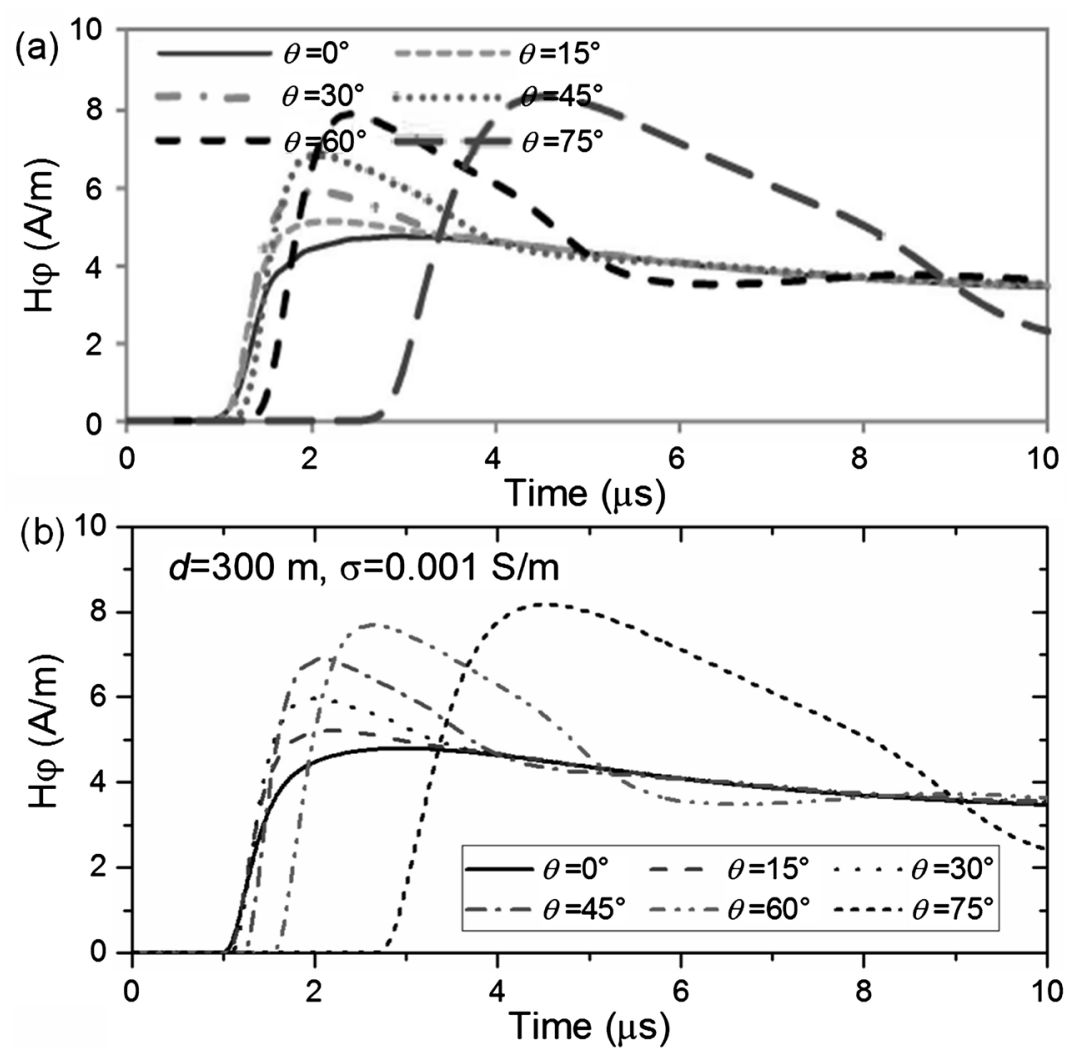

Figure 2. Compared simulated results between ours (b) and that presented by Paknahad et al. [20] (a).

line model with exponential decay model (MTLE) [29] [30] assuming a current decay constant $\lambda=2 \mathrm{~km}$ was adopted for representing the return stroke current along the channel. The channel length is assumed to be $\mathrm{H}=7.5 \mathrm{~km}$ and the return stroke velocity is set to be $\mathrm{v}=150 \mathrm{~m} / \mu \mathrm{s}$.

\subsection{Effect of the Mountain M2 on the Lightning Vertical Electric Field and Azimuthal Magnetic Field at the Different Observed Distance}

From Figure 1 there are several factors that may have much effect on the lightning electromagnetic field at the observed site on the ground level, in this paper we only analyze the effects caused by the top heights of M1, M2 and M3, and the observed site distance $\mathrm{d}$ from M3.

Figure 3 shows the computed lightning vertical electric field at the bottom of mountain M3 (see Figure 1), and the earth conductivity is $0.01 \mathrm{~S} / \mathrm{m}$. Assuming that lightning strikes that M1 mountain top with the heights of $1000 \mathrm{~m}$ and and the inclination angles of mountain M1 is assumed to be a constant of $45^{\circ}$, and the top height of mountain M2 ranges from 0 to $2000 \mathrm{~m}$.

It is found that the electrostatic shielding effect for the vertical electric field due to the mountain M3 is very obvious, with the increase of top height of the mountain M3, the shielding effect becomes more. From Figure 3(a) without the mountain M2, even the top height of mountain M3 is less than that of mountain 

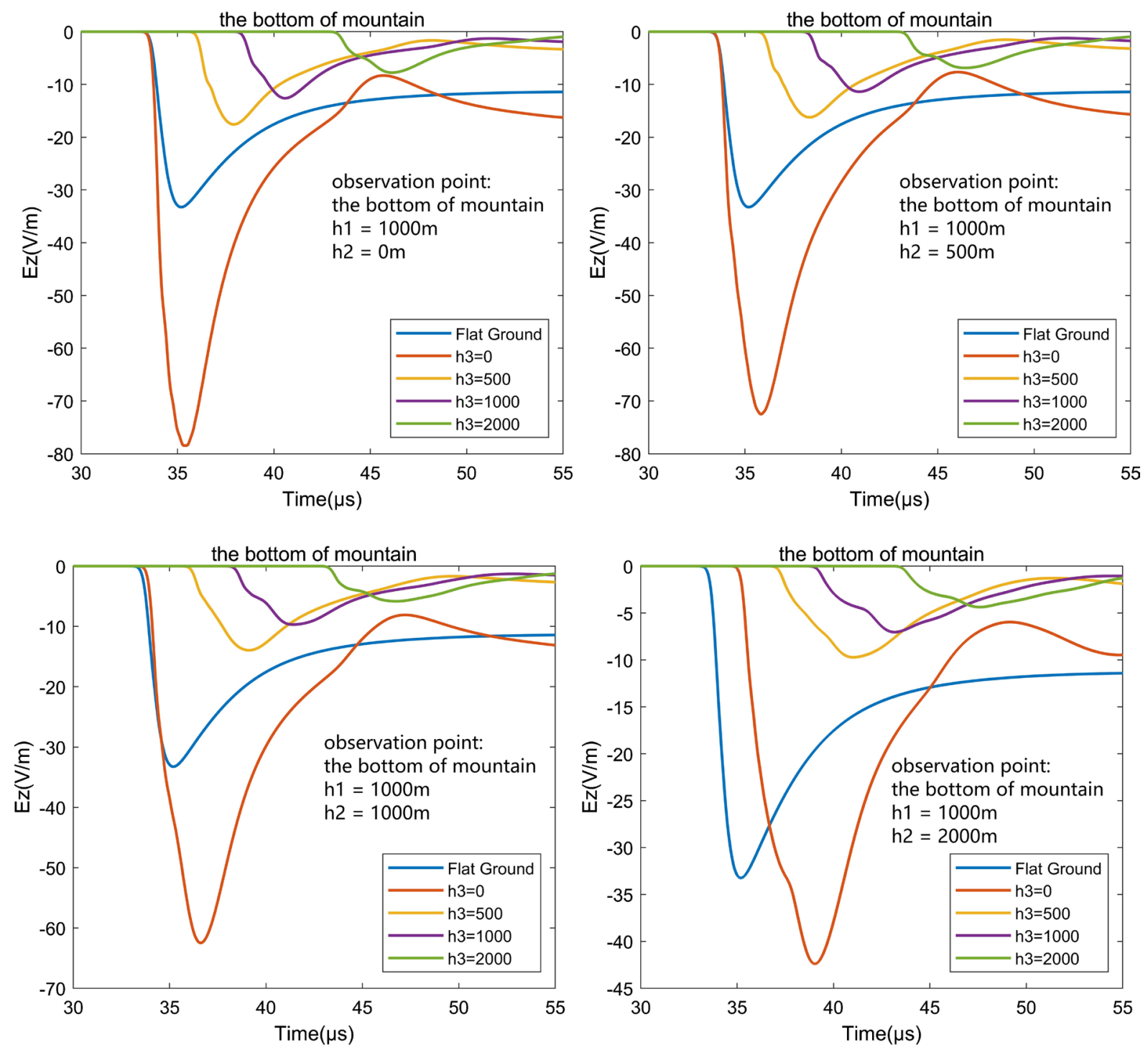

Figure 3. For the vertical electric field at the bottom of mountain terrain M3.

M1, the lightning vertical electric field is much less than that for strike to flat ground level, which means that the effect of mountain M3 on the lightning vertical electric field at its bottom is the most serious. It is worth noting that the reduction of the electric field near the mountain terrain is due to the electrostatic shielding effect caused by mountain terrain, but not due to the reflecting wave in the transition. Further analysis show that the electrostatic shielding effect of the higher and sharper mountain terrain will be more.

Therefore, if the observed site is very near the mountain M3, which means that we should pay more attention to the effect of mountain terrain near the observed site on the estimation of lightning current peak using observed electromagnetic field. The theoretical estimation expressions between the return stroke channel base currents and lightning electromagnetic field are usually assumed to be proportional to each other, with the proportionality coefficient being determined for strike to the flat ground similar to Figure 1(a). 
However, with the increase of distance, the electrostatic shielding effect caused by the mountain M3 decreases obviously due to the quick attenuation of the electrostatic field. At the same time, the reflected wave occurs at the transition between the cone-shape mountain and the flat plane and it plays a more important role in the lightning electric field over intermediate ranges, and the far radiation field peak value becomes larger due to such a reflecting wave. The far radiation field components are the superposition of the incident wave from the mountain top (lightning strike point) and the reflected wave at the transition. Therefore, compared with the computed field results in the bottom of mountain M3 at the close distance, the effect of mountain M3 becomes less. In this situation, although the mountain M3 with the top height of $3000 \mathrm{~m}$ is much taller than those of M1 and M2, the lightning vertical electric field at the distance of $20 \mathrm{~km}$ is still more than that for strike to the flat ground.

Therefore, near the bottom of the mountain M3 at the close distance, we should pay more attention to the electrostatic shielding effect, because the near field is primarily electrostatic component. While at the intermediate ranges, we should pay more attention to the reflected wave of the lightning radiation field from the transition between the mountain and the flat plane, because the intermediate far is primarily radiation field component.

Similar to that of Figure 3 and Figure 4, Figure 5 shows the computed lightning azimuthal magnetic field at the bottom of mountain M3 and at the intermediate distance of $20 \mathrm{~km}$ from M1. It is found that the magnetic field value for strike to the mountain M1 with the height of $1000 \mathrm{~m}$ is nearly 2 times as much as that for strike to flat ground (see the line for $\mathrm{h} 3=0$ ). However, with the increase of mountain height of M3, the lightning magnetic field obviously decreases due to the shielding effect caused by mountain terrain M3.

Also, the mountain M2 between the strike point and observed site has much effect on the magnetic field value, when the top height of the mountain M2 is larger than that of M1 and M3, the effect of the mountain M2 is dominant (see Figure 5). However, although the mountains M2 and M3 cause the reduction of magnetic field due to the shielding effect and the attenuation effect, respectively, for most cases, the lightning azimuthal magnetic field at the bottom of mountain M3 is larger than that for the ideal cases (see Figure 1(a) for the flat ground), mainly because of the increment caused by strike to the mountain M1.

Further, with the increase of distance, the shielding effect becomes less and the lightning azimuthal magnetic field is much more than that for strike to flat ground over intermediate ranges of $20 \mathrm{~km}$, mainly because of the increment caused by strike to the mountain M1.For example, from Figure 6, even the top heights of mountain M2 and M3 are taller about by $2-3$ times than that of mountain M1. Therefore, for the chains of hills, if the lightning strikes the mountain top, the lightning electromagnetic field becomes more than that for strike to flat ground.

Also, from Figures 3-6, we can see that the lightning field wave is propagating 

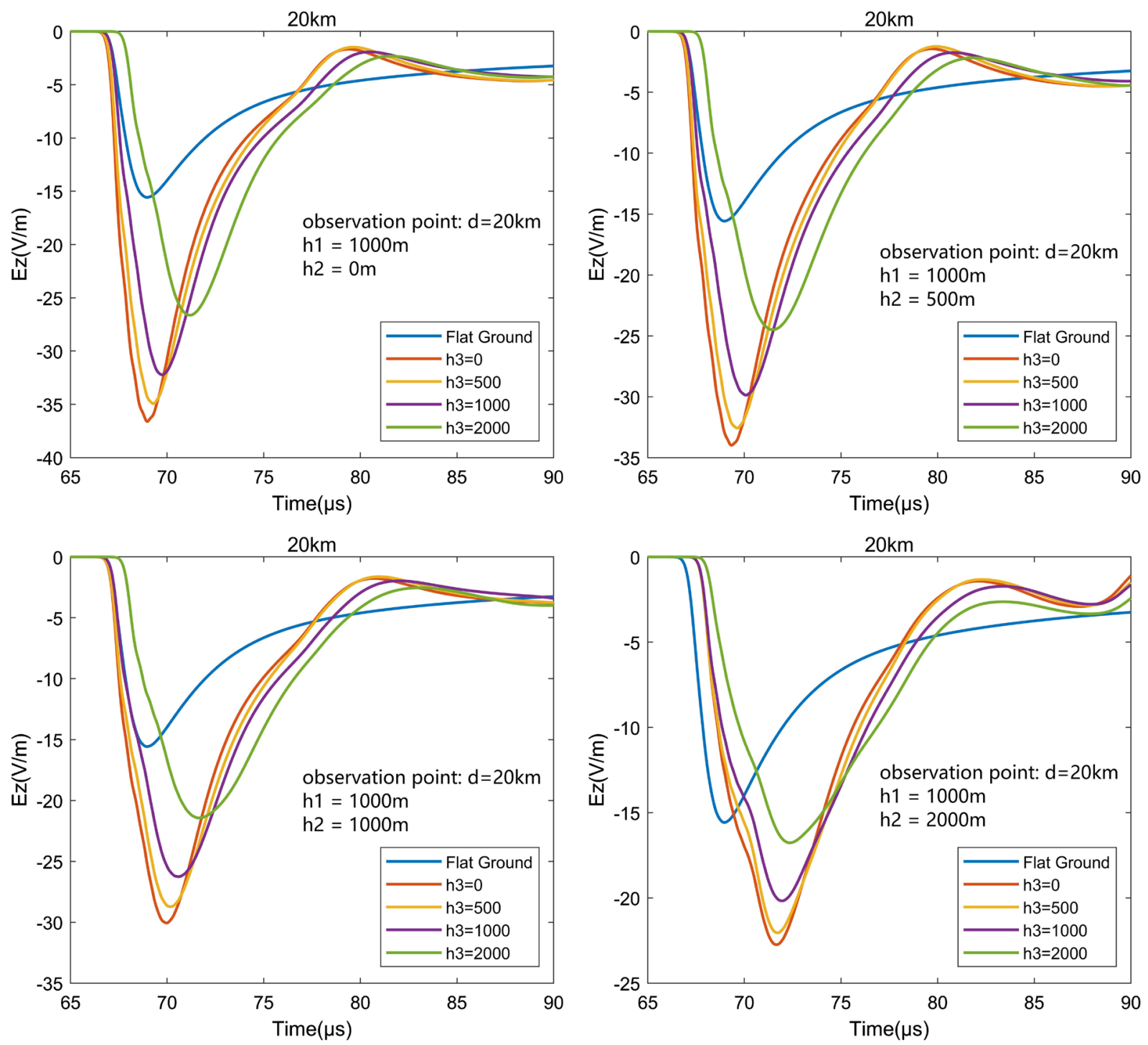

Figure 4. Same as that in Figure 3, but for the site of $20 \mathrm{~km}$ from the mountain M1.
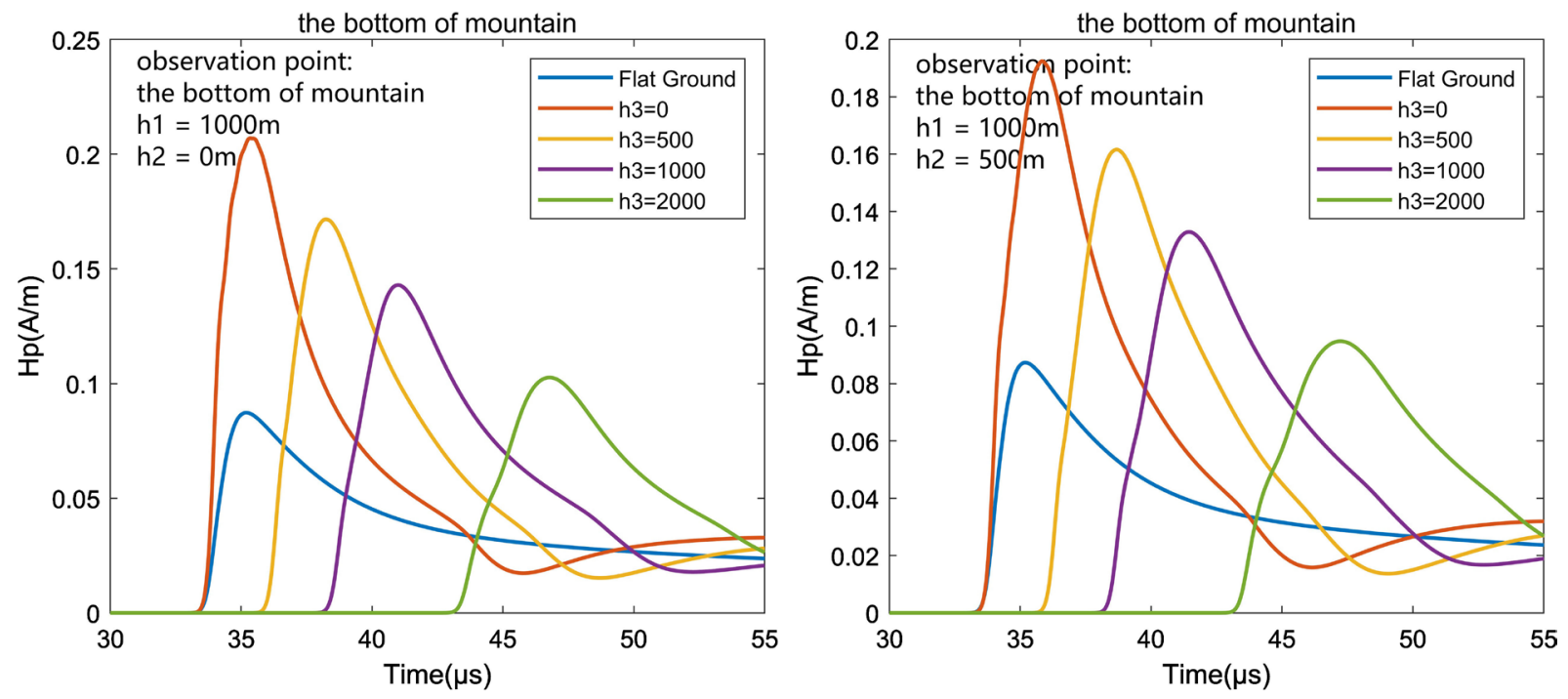

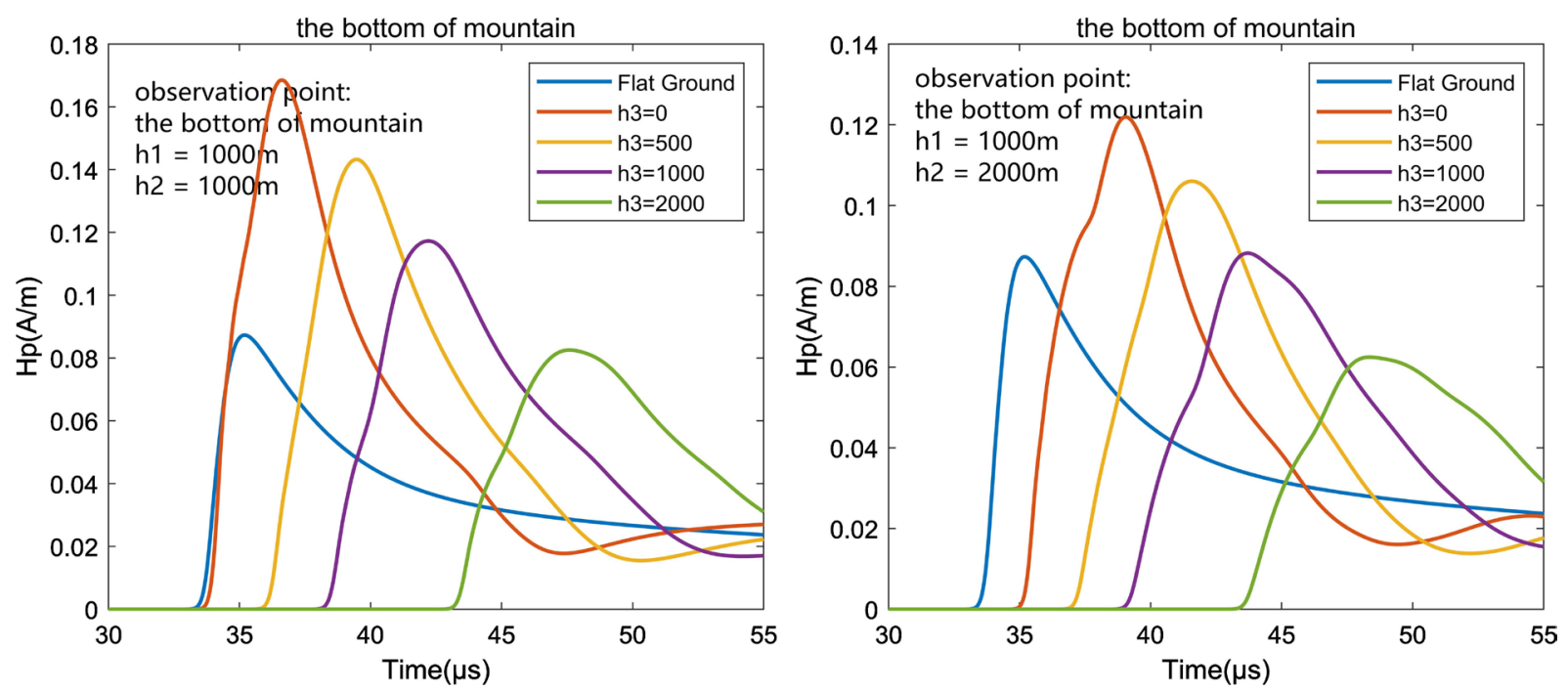

Figure 5. For the azimuthal magnetic field at the bottom of mountain M3.
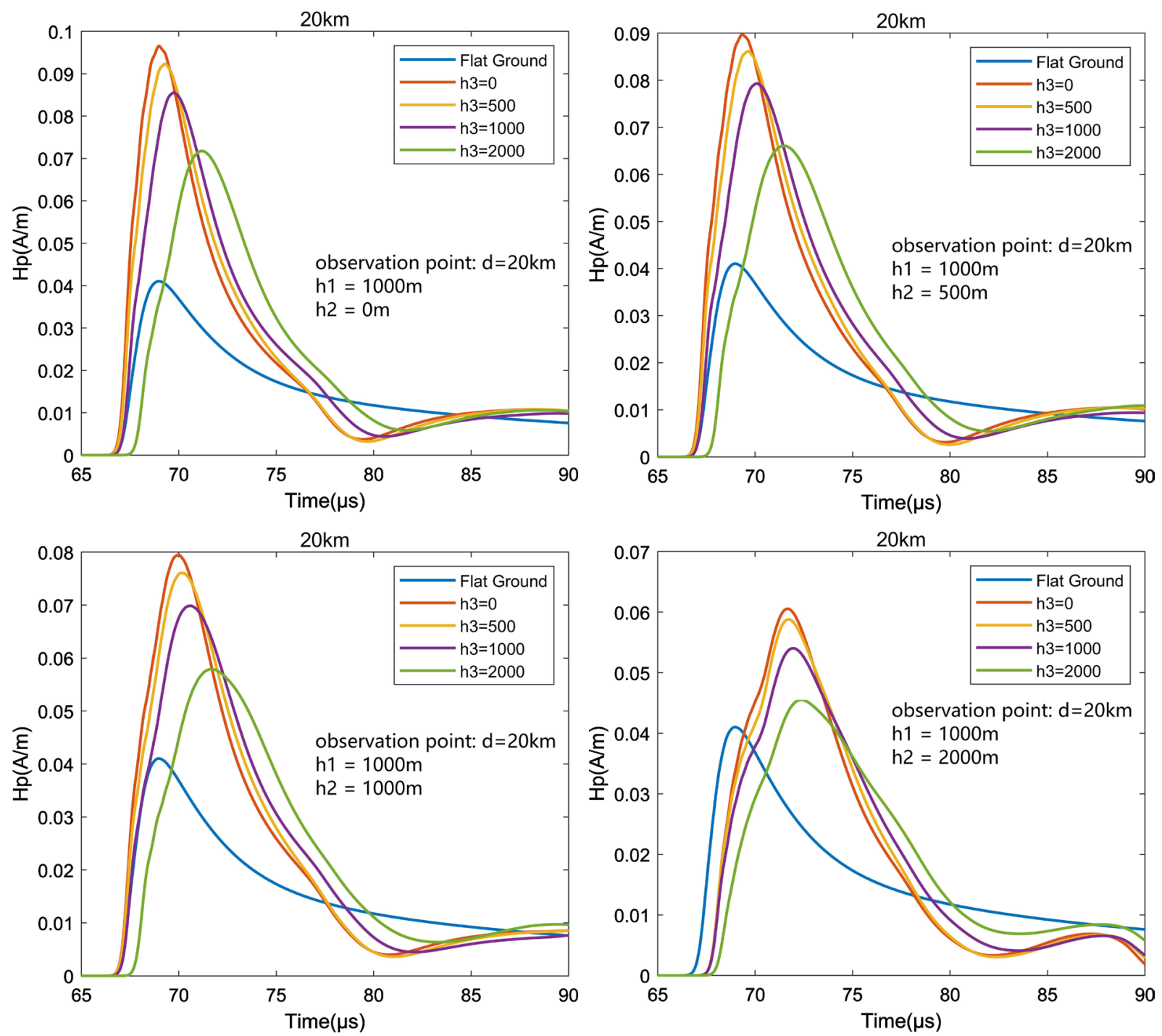

Figure 6. Same for Figure 3, but for the distance of $20 \mathrm{~km}$ from M1. 
along the earth surface, the time delay due to the mountain terrain is very obvious for the bottom of M3 at the close distance. However, for the distance of $20 \mathrm{~km}$, the time delay due to the mountain terrain becomes less. Therefore, we should pay more attention to the lightning location errors caused by the mountain terrains when using time of arrival (TOA) method, especially when the observation point is close to the mountain terrains.

\subsection{Effect of the Mountain M1 Stroke by Lightning on the Lightning Vertical Electric Field and Azimuthal Magnetic Field at Different Observed Distance}

Figure 7 and Figure 8 show the effect of the mountain M1 on the lightning vertical electric field and azimuthal magnetic field at different observed distance
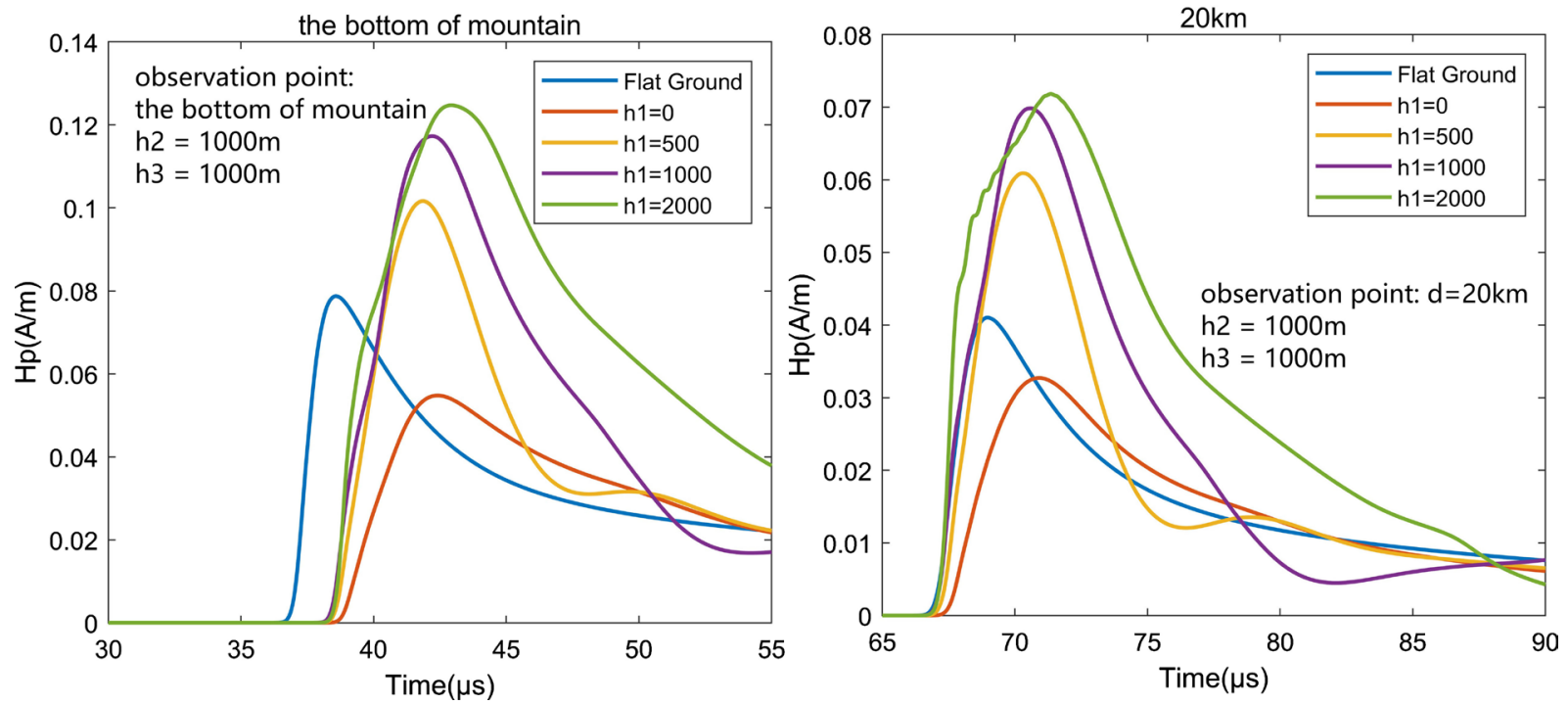

Figure 7. Effect of the mountain M1 stroke by lightning on the lightning azimuthal magnetic field at different observed distance.
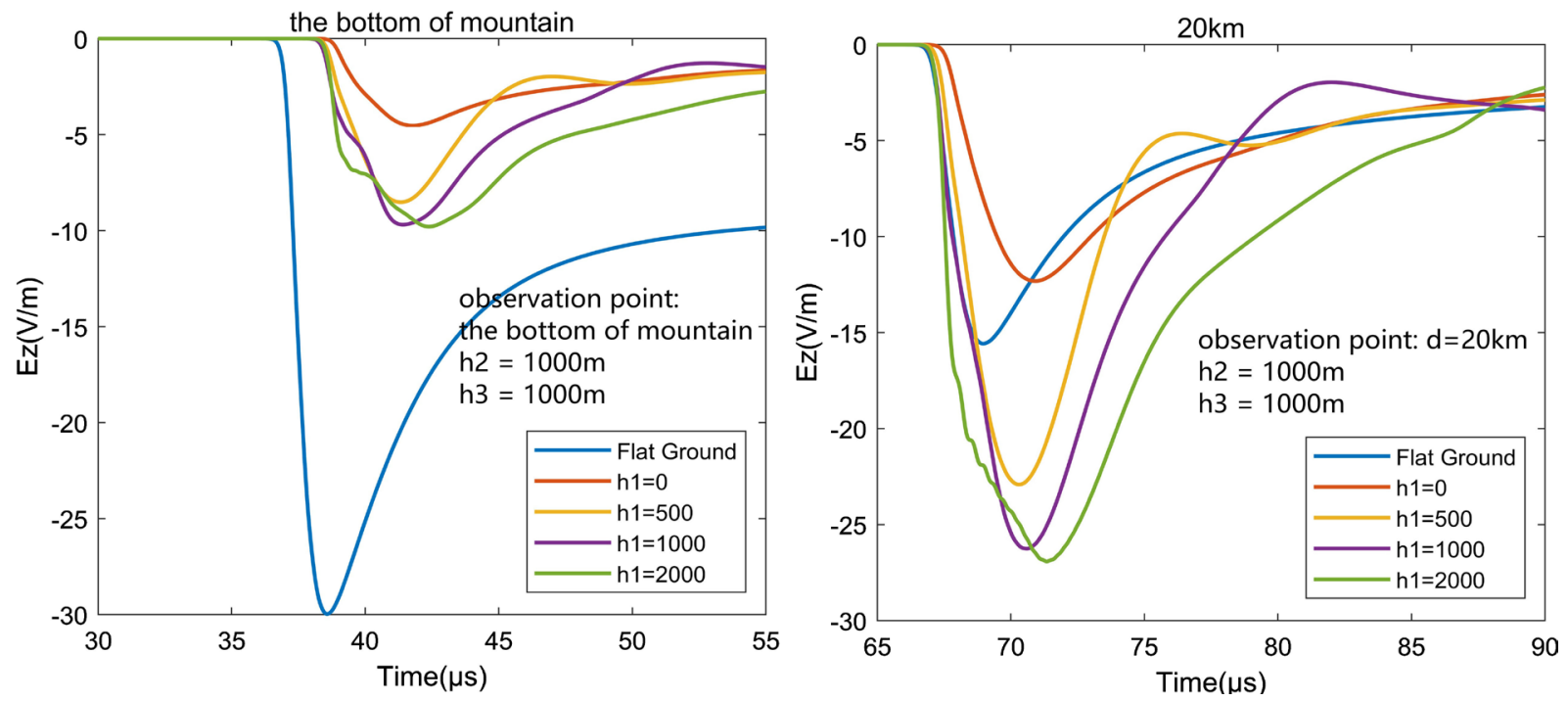

Figure 8. Same as that in Figure 7, but for lightning vertical electric field. 
(e.g., the bottom of mountain M3 and the distance of $20 \mathrm{~km}$ ), respectively. It is seen that with the increase of top height of mountain M1, for most cases, the corresponding lightning electromagnetic field value increases obviously. However, at the bottom of mountain M3, the shielding effect due to the mountain M3 for lightning vertical electric field is much more than that for lightning azimuthal magnetic field, and at the distance of $20 \mathrm{~km}$, the shielding effect obviously decreases.

\section{Conclusion}

In fact, the complex topography and geomorphology have much effect on the lightning electromagnetic field propagation (e.g., the field peak value and its arrival time), for example, in the lightning location technique, the arrival time of the lightning field wave is delay due to the complex topography and geomorphology, which will increase the lightning location error. Therefore, in this paper we have studied the effect of strike to a cone-shaped mountain surrounded by two chains of hills on the lightning vertical electric field and azimuthal magnetic field at different distances, by using two-dimensional finite-difference time-domain (2-D FDTD) method in cylindrical coordinate systems. Three mountains are assumed and the left one is stroke by lightning, and the right one is near the obervation site, and the middle one with the top heights increasing from 0 to $2 \mathrm{~km}$ is between them. Compared with the electric field, the shielding effect of the right one on the lightning azimuthal magnetic field becomes less, for most cases, the lightning magnetic field at the observed site is larger than that for flat ground cases mainly due to that of the increment caused by strike to the right mountain. With the increase of distance (e.g., $20 \mathrm{~km}$ from the lightning strike point), the shielding effect of the right mountain on the lightning field becomes less, because the reflected wave from the right mountain bottom plays a more important role over intermediate ranges, and the far radiation electromagnetic field peak value becomes larger due to such a reflecting wave. Therefore, in the lightning detecting technique, we should pay more attention to the effect caused by chains of hills on the lightning location and the estimation of lightning current peak, and we should pay more attention to the lightning location errors caused by the mountain terrains when using time of arrival (TOA) method, especially when the observation point is close to the mountain terrains.

\section{Conflicts of Interest}

The authors declare no conflicts of interest regarding the publication of this paper.

\section{References}

[1] Uman, M.A., McLain, D.K. and Krider, E.P. (1975) The Electromagnetic Radiation from a Finite Antenna. American Journal of Physics, 43, 33-38. 
https://doi.org/10.1119/1.10027

[2] Rakov, V. and Uman, M.A. (1998) Review and Evaluation of Lightning Return Stroke Models Including Some Aspects of Their Application. IEEE Transactions on Electromagnetic Compatibility, 40, 403-426. https://doi.org/10.1109/15.736202

[3] Rachidi, F., Bermudez, J.L., Rubinstein, M. and Rakov, V.A. (2004) On the Estimation of Lightning Peak Currents from Measured Fields Using Lightning Location Systems. Journal of Electrostatics, 60, 121-129. https://doi.org/10.1016/j.elstat.2004.01.010

[4] Azadifar, M., Rachidi, F., Rubinstein, M., et al. (2016) Evaluation of the Performance Characteristics of the European Lightning Detection Network EUCLID in the Alps Region for Upward Negative Flashes Using Direct Measurements at the Instrumented Säntis Tower. Journal of Geophysical Research: Atmospheres, 121, 595-606. https://doi.org/10.1002/2015JD024259

[5] Li, D., et al. (2016) On Lightning Electromagnetic Field Propagation along an Irregular Terrain. IEEE Transactions on Electromagnetic Compatibility, 58, 161-171. https://doi.org/10.1109/TEMC.2015.2483018

[6] Motoyama, H., Janischewskyj, W., Hussein, A.M., Rusan, R., Chisholm, W.A. and Chang, J.S. (1996) Electromagnetic Field Radiation Model for Lightning Strokes to Tall Structures. IEEE Transactions on Power Delivery, 11, 1624-1632. https://doi.org/10.1109/61.517526

[7] Rachidi, F., Janischewskyj, W., Hussein, A.M., Nucci, C.A., Guerrieri, S., Kordi, B. and Chang, J.S. (2001) Current and Electromagnetic Field Associated with Lightning-Return Strokes to Tall Objects. IEEE Transactions on Electromagnetic Compatibility, 43, 356-367. https://doi.org/10.1109/15.942607

[8] Baba, Y. and Rakov, V.A. (2005) Lightning Electromagnetic Environment in the Presence of a Tall Grounded Strike Object. Journal of Geophysical Research: Atmospheres, 110. https://doi.org/10.1029/2004JD005505

[9] Baba, Y. and Rakov, V.A. (2007) Lightning Strikes to Tall Objects: Currents Inferred from Far Electromagnetic Fields versus Directly Measured Currents. Geophysical Research Letters, 34, L19810. https://doi.org/10.1029/2007GL030870

[10] Hussein, A.M., Milewski, M. and Janischewskyj, W. (2008) Correlating the Characteristics of the CN Tower Lightning Return-Stroke Current with Those of Its Generated Electromagnetic Pulse. IEEE Transactions on Electromagnetic Compatibility, 50, 642-650. https://doi.org/10.1109/TEMC.2008.924398

[11] Pavanello, D., Rachidi, F., Janischewskyj, W., Rubinstein, M., Shostak, V.O., Nucci, C.A., Cummins, K.L., Hussein, A.M. and Chang, J.-S. (2009) On the Current Peak Estimates Provided by Lightning Detection Networks for Lightning Return Strokes to Tall Objects. IEEE Transactions on Electromagnetic Compatibility, 51, 453-458. https://doi.org/10.1109/TEMC.2009.2025913

[12] Bermudez, J.L., Rachidi, F., Janischewskyj, W., Shostak, V., Rubinstein, M., Pavanello, D., Hussein, A.M., Chang, J.S., Nucci, C.A. and Paolone, M. (2005) Far-Field-Current Relationship Based on the TL Model for Lightning Return Strokes to Elevated Strike Objects. IEEE Transactions on Electromagnetic Compatibility, 47, 146-159. https://doi.org/10.1109/TEMC.2004.842102

[13] Bermudez, J.L., Rachidi, F., Janischewskyj, W., Shostak, V., Rubinstein, M., Pavanello, D., Hussein, A.M., Chang, J.S. and Paolone, M. (2007) Determination of Lightning Currents from Far Electromagnetic Fields: Effect of a Strike Object. Journal of Electrostatics, 56, 289-295. https://doi.org/10.1016/j.elstat.2006.09.007

[14] Rachidi, F. (2007) Modeling Lightning Return Strokes to Tall Structures: A Review. 
Journal of Lightning Research, 1, 16-31.

[15] Mosaddeghi, A., Shoory, A., Rachidi, F., Diendorfer, G., Pichler, H., Pavanello, D., Rubinstein, M., Zweiacker, P. and Nyffeler, M. (2010) Lightning Electromagnetic Fields at Very Close Distances Associated with Lightning Strikes to the Gaisberg Tower. Journal of Geophysical Research, 115, D17101. https://doi.org/10.1029/2009JD013754

[16] Zhang, Q., He, L., Ji, T. and Hou, W. (2014) On the Field-to-Current Conversion Factors for Lightning Strike to Tall Objects Considering the Finitely Conducting Ground. Journal of Geophysical Research, 119, 8189-8200. https://doi.org/10.1002/2014JD021496

[17] Zhang Q., Hou W., Ji T., He, L. and Su J. (2014) Validation and Revision of Far-Field-Current Relationship for the Lightning Strike to Electrically Short Objects. Journal of Atmospheric and Solar-Terrestrial Physics, 120, 41-50. https://doi.org/10.1016/j.jastp.2014.08.015

[18] Soto, E., Perez, E. and Herrera, J. (2014) Electromagnetic Field Due to Lightning Striking on Top of a Cone-Shaped Mountain Using the FDTD. IEEE Transactions on Electromagnetic Compatibility, 56, 1112-1120. https://doi.org/10.1109/TEMC.2014.2301138

[19] Soto, E., Perez, E. and Younes, C. (2014) Influence of Non-Flat Terrain on Lightning Induced Voltages on Distribution Networks. Electric Power Systems Research, 113, 115-120. https://doi.org/10.1016/j.epsr.2014.02.034

[20] Paknahad, J., Sheshyekani, K., Hamzeh, M. and Rachidi, F. (2014) Lightning Electromagnetic Fields and Their Induced Voltages on Overhead Lines: The Effect of a Non-Flat Lossy Ground. In: Proceedings of 32nd International Conference on Lightning Protection, Shanghai, 591-594. https://doi.org/10.1109/ICLP.2014.6973193

[21] Khosravi, R., Sadeghi, S.H.H. and Moini, R. (2016) Electromagnetic Field Due to Lightning Strike to a Tall Tower Sitting on a Mountainous Terrain. IEEE Transactions on Electromagnetic Compatibility, 58, 1090-1099. https://doi.org/10.1109/TEMC.2016.2551301

[22] Yee, K.S. (1966) Numerical Solution of Initial Boundary Value Problems Involving Maxwell's Equations in Isotropic Media. IEEE Transactions on Antennas and Propagation, AP-14, 302-307. https://doi.org/10.1109/TAP.1966.1138693

[23] Yang, C. and Zhou, B. (2004) Calculation Methods of Electromagnetic Fields Very Close to Lightning. IEEE Transactions on Electromagnetic Compatibility, 46, 133-141. https://doi.org/10.1109/TEMC.2004.823626

[24] Roden, J.A. and Gedney, S.D. (2000) Convolution PML (CPML): An Efficient FDTD Implementation of the CFS-PML for Arbitrary Media. Microwave and Optical Technology Letters, 27, 334-339. https://doi.org/10.1002/1098-2760(20001205)27:5<334::AID-MOP14>3.0.CO;2-A

[25] Baba, Y. and Rakov, V.A. (2005) On the Use of Lumped Sources in Lightning Return Stroke Models. Journal of Geophysical Research, 110, D03101. https://doi.org/10.1029/2004JD005202

[26] Jurgens, T.G., Taflove, A., Umashankar, K. and Moore, T.G. (1992) Finite-Difference Time-Domain Modeling of Curved Surfaces. IEEE Transactions on Antennas and Propagation, 40, 357-366. https://doi.org/10.1109/8.138836

[27] Yu, W. and Mittra, R. (2001) A Conformal Finite Difference Time Domain Technique for Modeling Curved Dielectric Surfaces. IEEE Microwave and Wireless Components Letters, 11, 25-27. https://doi.org/10.1109/7260.905957 
[28] Heidler, F., Cvetic, J. and Stanic, B.V. (1999) Calculation of Lightning Current Parameters. IEEE Transactions on Electromagnetic Compatibility, 14, 399-404. https://doi.org/10.1109/61.754080

[29] Nucci, C.A., Mazzetti, C., Rachidi, F. and Ianoz, M. (1988) On Lightning Return Stroke Models for LEMP Calculations. Presented at the 19th International Conference Lightning Protection, Graz, Austria.

[30] Rachidi, F. and Nucci, C.A. (1990) On the Master, Uman, Lin, Standler and the Modified Transmission Line Lightning Return Stroke Current Models. Journal of Geophysical Research: Atmospheres, 95, 20389-20393.

https://doi.org/10.1029/JD095iD12p20389 